\title{
INFLUÊNCIAS EM IHERING: investigação dos fundamentos de seu pensamento em sua fase madura*
}

\author{
Bruno Bozon Lauda'
}

\begin{abstract}
RESUMO: o presente trabalho trata-se de uma análise comparativa entre os dois principais escritos de lhering de sua fase madura e trabalhos de filósofos, juristas e economistas ingles es da corrente filosófica do utilitarismo, como forma de se tentar estabelecer se houve ou não influências de sua parte sobre o pensamento maduro de lhering, em sua segunda fase, chamada de "jurisprudência dos interesses".
\end{abstract}

PALAVRAS-CHAVE: história do direito, juristas ingleses, juristas alemães, pragmatism, utilitarismo

\section{INFLUENCES OVER IHERING: an investigation of the fundaments of his thought on his mature phase}

ABSTRACT: the present article is a comparative analysis between the two main writings of the german jurist Rudolf von Ihering in his mature phase and the works of the philosophers, lawyers and English economists of the philosophical school known as utilitarianism, as a way of trying establish whether or not there were influences of their works over the mature lhering, in his second phase, known as the "jurisprudence of interests."

KEY-WORDS: history of law, english jurists, german jurists, pragmatism, utilitarianism

\footnotetext{
“ Texto elaborado para a Disciplina DIRP - 150", ministrada pelo Prof. Dr. Alfredo de Jesus Dal Molin Flores, no $2^{\circ}$ semestre do ano letivo de 2009.

${ }_{1}$ Aluno do programa de pós-graduação em Direito da Universidade Federal do Rio Grande do Sul (UFRGS), matrícula no 00138368.
} 


\section{INTRODUÇÃO}

O objetivo do presente trabalho é o de realizar um estudo acerca da última fase do pensamento do jurista alemão do século XIX Rudolf von Ihering. Serão analisados os caracteres fundamentais de seu pensamento maduro, bem como se tentará buscar as possíveis influências que se lhe abateram.

Para tanto, serão objeto de análise as duas obras de expressão máxima de lhering em sua fase madura, a que acreditamos estar consolidada a partir do Espírito do Direito Romano ${ }^{2}$ (1852/1865), o jurista da chamada “jurisprudência dos interesses”, cuja obra máxima é O Fim do Direito (18771883) $)^{3}$.

Não foi realizada uma análise histórico-biográfica, com o uso de fontes primárias, como cartas, e secundárias, como relatos, mas sim apenas um estudo literário, com a utilização dos dois principais escritos do autor já mencionados, representantes de uma fase e de outra. A idéia é a de comparar o pensamento do autor tal como chegou até nós.

A guisa de introdução colocamos desde já que nos parece que lhering, tal como outros pensadores alemães de sua época ${ }^{4}$, sofreu grandes influências da filosofia anglo-saxã, em especial a utilitarista, de Jeremy Bentham e seus seguidores. Por isso será necessária alguma introdução às idéias gerais desses autores.

Inicialmente realizar-se-á uma breve referência à biografia de lhering, com menção às datas de publicação de suas principais obras, dado que é necessário para situarmo-nos no tempo em relação à vida do autor para o presente estudo.

\footnotetext{
2 "Der Geist des römischen", no original.

3 "Zweck im Recht", no original. Foi traduzido para a língua portuguesa também sob o título de "A Evolução do Direito". A tradução realizada para a língua inglesa parece-nos igualmente acertada, em relação à proposta do autor: "Teleology of Law". Pois a palavra "Fim", adotada na tradução para a língua portuguesa, indica tanto finalidade no sentido de teleologia como no de explicação de uma relação de causalidade (necessária ou não), ficando pouco claro de qual se trata antes da leitura da obra, pecando pela ambigüidade. Por outro lado, o vocábulo "evolução" é postiçamente científico e sugere neutralidade e naturalidade de um dado processo, que no caso seria o das sucessivas manifestações do Direito na história, conceitos que não condizem com a proposta do trabalho de Ihering. Pois, a obra trata da "evolução do Direito" em um sentido definido (o qual é mencionado no presente artigo). No entanto, "evolução" por si só não indica nenhuma finalidade, e sim apenas uma série de transformações adaptativas ou de aprimoramentos sem vínculos com qualquer logos - isto é, não sugere qualquer teleologia. No entanto, é importante ressaltar que esse fim é essencialmente prático, em Ihering, e não, de qualquer modo, transcendental. Por isso a tradução para a língua inglesa também não é exata.

${ }^{4}$ Mencionamos o exemplo de Marx, antes e depois de O Capital.
} 


\section{A PRIMEIRA FASE DE IHERING}

Ihering nasceu no dia vinte e dois de Agosto de 1818, em Aurich, na Frísia. Filho de família de eminentes e tradicionais juristas, jamais manifestou dúvidas quanto à sua vocação.

Estudou em várias universidades: começou em Heidelberg, completando sua formação inicial em Göttingen, e depois em Berlim, em cuja Universidade se graduou em 1843.

Ainda durante a graduação, adquiriu tal renome que foi convidado para lecionar na Basiléia, Suíça, com vinte e sete anos de idade, indo depois lecionar sucessivamente, em Kiel, Giessen, onde escreveu seu principal trabalho sobre Direito Romano e, finalmente, em Viena, onde se notabilizou como professor de Direito Romano, tendo sido-Ihe concedido inclusive um título de nobreza.

Em Viena, ao mesmo tempo em que lecionava, continuava a redigir o livro "O Espírito do Direito Romano nas Diversas Fases de sua Evolução". É nesta fase de sua vida que adentra na maturidade de seu pensamento, na qual Ihering escreveu sua obra definitiva: "Zwerk der Recht" ("A Finalidade do Direito"), em 1883, quando já estava vivendo em Göttingen (e onde permaneceu até a sua morte).

Os escritos de lhering se caracterizam por manifestar suas críticas para com o grande jurista da geração passada, Savigny. O fundamento de seu Espírito do Direito Romano não é nenhum outro senão uma reação contrária à percepção que tinha de que o Tratado de Direito Romano daquele autor partiria de uma visão puramente nacionalista, e até solipsista do Direito Alemão. Nesse sentido:

\footnotetext{
"A escola histórica, diz Savigny, ao formular o seu programa, admite que a substância do Direito seja dada por todo o passado de uma nação, não certamente de um modo arbitrário e determinado tão somente pelo acaso, mas sim saindo das próprias entranhas dessa nação e de sua história. Como se vê, é a condenação do próprio Direito romano. Que há de comum entre o Direito romano e todo o passado, as próprias entranhas e a história das nações modernas?" 5
}

\footnotetext{
${ }^{5}$ IHERING, Rudolf Von. Espírito do direito romano. p. 13.
} 
Para Ihering, pois, o erro da escola histórica teria consistido em sua defesa do caráter nacional, do volksgeist relativo ao Direito como elemento fundamental. Em posição que iria manter em seus trabalhos posteriores, no Espírito a crítica de Ihering a essa posição pode ser resumida ao apontamento de uma aparente obviedade: inexistem Direitos verdadeiramente nacionais dentre os que se serviram do Direito romano. Nesse sentido:

\begin{abstract}
"O Direito romano, dizem, chegou a ser, com o transcurso dos anos, o nosso, e, evitando a controvérsia, crêem poder defendê-lo com o princípio das nacionalidades. Isso é possível; mas como se justificará que o Direito romano se haja transformado em nosso direito? Quando, pela primeira vez, bateu à nossa porta, certamente ainda não o era (...) Eis aí o problema que a escola de se trata [histórica] deixa sem resposta (...) mas dadas as suas conclusões, a aceitação do Direito romano não se compreende senão como um extravio inexplicável da história como uma apostasia do princípio histórico (...)."
\end{abstract}

Ihering adota um ponto de vista fortemente universalista. Tudo, no Direito Romano, que dissesse respeito exclusivamente às peculiaridades da nação romana, e que não tivesse chegado até nós como manifestação direta em algum instituto, foi tratado como sendo relevante apenas de um ponto de vista filológico. Seu objetivo era o de ressaltar os aspectos universais do Direito Romano, e não o de escrever uma obra sobre história em sentido estrito.

Na obra, a evolução do Direito Romano é tratada como se fosse um processo de evolução psicológica e social. O objetivo proposto é o de extrair o espírito do Direito para o romano e para a sua era. Por isso, Ihering reconstrói a mentalidade da época da qual tratava. Não se trata de uma análise filológica e histórica pura, mas sim de um estudo cultural. Ihering não $\circ$ fez inconscientemente:

"A maior parte dos trabalhos que contém a exposição da história do
Direito romano parecem contradizer formalmente esta opinião. Em
vez de demonstrar a unidade histórica do conjunto das instituições,
não desenvolvem, às nossas vistas, mais do que uma série de trocas
sem relação entre si. Dividem a matéria em história interna e história
externa: esta última em períodos (método sincronístico) enquanto que
para a outra abandonam essa divisão (método cronológico). (...) Para
que se possa falar de uma história do direito é absolutamente

${ }^{6}$ lbidem, p. 13-14. 
necessário supor certa proporção e simultaneidade no jogo das diversas instituições."

Podem-se vislumbrar os pontos fundamentais de Ihering diante do que já foi exposto. Primeiro, um crítico da escola histórica, por conta de seu - alegado - nacionalismo. Para Ihering, um estudo acerca da natureza do Direito não poderia jamais pretender-se completo atendo-se apenas à realidade jurídica de um único país, e, mais do que isso, um estudo da história do Direito em um determinado país não poderia limitar-se apenas ao estudo das fontes daquele mesmo país, e sim incluir tudo o que lhe fosse comparável do estrangeiro.

Segundo, seu objetivo fundamental: encontrar o valor para a vida do Direito. Por isso o seu Espírito não é comparável a outras obras posteriores, e mesmo anteriores, em termos de fontes e pesquisa histórica criteriosa: seu objetivo principal foi o de buscar o significado cultural e social do Direito romano. O objetivo de Ihering não é mais tanto obter um conhecimento total da do Direito, mas sim, o que desenvolveria em sua grande obra posterior, seu fim.

De acordo com LARENZ, se nota ainda o fenecimento da influência da "jurisprudência dos conceitos" de Puchta ${ }^{8}$, predominante no pensamento do autor antes da maturidade, para uma jurisprudência mais pragmática: a jurisprudência dos interesses.

\section{A “JURISPRUDÊNCIA DOS INTERESSES": INFLUÊNCIAS E}

\section{PRESSUPOSTOS}

O contexto em que Ihering lecionou não Ihe era amigável. Ocorre que, à época, sofria, a academia alemã de uma aversão quase que patológica ao utilitarismo e à ciência econômica de uma maneira geral (o que pode indicar o fato de que houve poucos economistas de renome de origem alemã, fora os austríacos) $)^{9}$. Em sua "segunda fase", eram-Ihe patentes as insuficiências e os

\footnotetext{
${ }^{7}$ IHERING, Rudolf Von. Espírito do direito romano. p. 54-55.

8 LARENZ, Karl. Metodologia da ciência do direito. Trad. José Lamego. 3a ed. Lisboa: Calouste Gulbenkian, 1997, p. 29.

${ }^{9} \mathrm{O}$ caso de lhering é, inclusive, citado brevemente por um dos mais eminentes economistas formados na escola de Viena, ao final do séc. XIX, o austríaco Ludwig Von Mises, que coloca, de maneira bastante contundente: "No less serious was the matter of utilitarianism. The utilitarian philosophy was not tolerated at German universities. Of the two outstanding German utilitarians, Ludwig Feuerbach never got any teaching job, while Rudolf von Jhering was a teacher of Roman Law. All the misunderstandings that for more than two thousand years have
} 
problemas da jurisprudência dos conceitos, então dominante. Segundo LARENZ:

\begin{abstract}
"De fato, uma ciência do Direito que via o seu maior contributo na compreensão historicamente fiel das fontes jurídicas romanas ainda estimadas como válidas para a atualidade e na inserção num sistema de conceitos logicamente inquestionável (e que, nesse as pecto, muito fizera de excelente) mal podia corresponder às exigências de uma prática do Direito que diuturnamente era colocada perante problemas a que aquelas fontes não conseguiam dar uma resposta satisfatória.(...)Era o mundo de idéias políticas que tinha emergido da Revolução Francesa." ${ }^{10}$
\end{abstract}

Assim, lhering percebera os principais problemas da escola. A adesão a um formalismo excessivo deturpava a ciência jurídica e não correspondia à verdadeira natureza do Direito. Além disso, pecava por não conseguir responder aos anseios da sociedade. O formalismo encerrava-se em fórmulas desligadas de seu tempo, fazendo com que os conceitos jurídicos perdessem o seu sentido prático ${ }^{11}$.

Assim, Ihering tinha de encontrar-Ihe e opor-lhe uma resposta. Nesse sentido, Ihering parece ter sofrido alguma influência pelos economistas ingleses clássicos e pelos utilitaristas, como Adam Smith, Jeremy Bentham e James Mill.

A conferir, por exemplo, a seguinte citação, de lhering:

“(...) A ampliação de minha fábrica exige que meu vizinho ceda parte do seu terreno. (...) Através da minha oferta de aquisição, crio, de forma artificial, na pessoa do meu vizinho, um interesse na realização da minha finalidade, desde que lhe ofereça uma quantia tal que seu interesse em abrir mão de seu direito à terra seja maior do que em conservá-la...."12

Tal passagem guarda incríveis semelhanças com Adam Smith, a saber, em seu famoso exemplo do padeiro:

been advanced against Hedonism and Eudaemonism were rehashed by the professors of Staatswissenschaften in their criticism of the British economists. If nothing else had roused the suspicions of the German scholars, they would have condemned economics for the sole reason that Bentham and the Mills had contributed to it." MISES, Ludwig. The Historical Settings of the Austrian School of Economics. Disponível em: http://mises.org/etexts/Histsetting.pdf. Acesso em: 09/11/2009.

${ }_{10}$ LARENZ, Karl. Metodologia da ciência do direito. Trad. José Lamego. 3a ed. Lisboa: Calouste Gulbenkian, 1997, p. 56.

11 Ihering, Rudolf von. A evolução do direito. p. 48.

${ }^{12}$ MORRIS, Clarence (org.). The great legal philosophers: selected readings in jurisprudence. Philadelphia: University of Pennsylvania Press, 1997. 
“(...) Não é da benevolência do padeiro, do açougueiro ou do cervejeiro que eu espero que saia o meu jantar, mas sim do empenho deles em promover seu próprio 'auto-interesse."13

E ainda com Jeremy Bentham. Comparemos, por exemplo, Ihering com Bentham, ao explicar o princípio da utilidade, ponto-chave da doutrina utilitarista:

"By the principle of utility is meant that principle which approves or disapproves of every action whatsoever, according to the tendency which it appears to have to augment or diminish the happiness of the party whose interest if in question(...). I say that of every action whatsoever, and therefore not only of every private individual, but of every measure of government." 14

Ihering, ao explicar as finalidades da vida social (isto é, o que buscam os governos e os particulares, individualmente considerados):

“(...) As finalidades da vida social também só podem ser atingidas movendo-se o outro lado com a alavanca do interesse, só que o interesse aqui é de uma natureza diferente daquela que é empregada na vida comercial. Aqui é o interesse de entretenimento, de distração, de prazer, de vaidade, de ambição, de respeito social, etc."

As influências dos utilitaristas foram importantes no pensamento maduro de lhering. Ainda que acabasse por não aderir a um utilitarismo extremado, ou a um pragmatismo inconseqüente, podem-se perceber duas características marcantes na fase madura do pensamento de lhering: Direito é coação exercida por meio da norma, a qual visa uma utilidade.

Ademais, é realmente patente a sua leitura e compreensão dos economistas clássicos. Em diversas passagens de sua obra O Fim do Direito, Ihering celebra as vantagens e os benefícios advindos da economia de livre mercado, como se fosse um Bastiat ou um Spencer. A ver, por exemplo:

"O egoísmo do vendedor que exagera o seu preço é paralisado pelo de outro mercador que prefere vender por um preço módico a não vender de maneira nenhuma; o egoísmo do comprador que oferece

\footnotetext{
${ }^{13}$ SMITH, Adam. A riqueza das nações: investigação sobre sua natureza e causas. Trad. Luiz João Baraúna. 2. ed. São Paulo: Nova Cultural, 1996. v. I e II (Os Economistas).

${ }^{14}$ MORRIS, Clarence (org.). The great legal philosophers: selected readings in jurisprudence. Philadelphia: University of Pennsylvania Press, 1997.
} 
muitíssimo pouco é paralisado pelo de um outro que oferece mais - a concorrência é o regulador espontâneo do egoísmo." ${ }^{15}$

Arrematando, em passagem de clareza inquestionável, colocando o mercado como o maior, melhor e mais eficiente promotor da igualdade:

\begin{abstract}
"Em parte alguma o princípio da igualdade se acha mais completamente realizado na prática (no comércio jurídico). O dinheiro é o verdadeiro apóstolo da igualdade. Os preconceitos sociais, todas as antíteses sociais, políticas, religiosas, nacionais, são impotentes contra ele. (...) Servindo-se a si próprio, favorece a família humana; preocupado somente consigo próprio e com o seu interesse, realiza no seu domínio sem o saber e sem querer um princípio que a ele resiste em qualquer outra parte - o da igualdade das pessoas." 16
\end{abstract}

Ou, ainda, como advogado do não-intervencionismo, tanto em termos históricos como propositivos:

"O comércio, as diferentes artes manuais, a agricultura, a indústria, a arte e a ciência, os costumes domésticos e os da vida organizam -se essencialmente por si próprios. O Estado só intervém por via do seu direito quando e unicamente essa intervenção é absolutamente necessária para preservar certos ataques à ordem que seus fins traçaram a si próprios." ${ }^{17}$

Apesar de tudo, no entanto, Ihering não foi um defensor do liberalismo extremado, admitindo intervenções estatais para o bem da sociedade, às custas da liberdade individual, criticando Mill, nesse sentido, por exemplo, em relações às questões da liberdade de comércio (mencionando o caso do ópio). Sua adesão ao liberalismo econômico foi bastante superficial. Ihering crítica a excessiva liberdade contratual e de comércio:

"E depois, que estranha suscetibilidade esta quando se trata de livre câmbio: [citando liberais] "Há no comércio questões relativas à intervenção pública que são essencialmente questões de liberdade; tais são: a proibição da exportação de ópio para a China, a restrição importa à venda de peixe, e, em suma, todos os casos em que o objeto da intervenção é tornar o comércio de certos gêneros difícil ou impossível. Essas intervenções são repreensíveis como verdadeiras usurpações cometidas, não já contra a liberdade do produtor, mas contra a do comprador." Portanto, o governo chinês não tem o direito de proibir o comércio do ópio? Deve então cruzar os braços e assistir a ruína física e moral do povo? (...) Sobre esta questão os dois

\footnotetext{
${ }^{15}$ IHERING, Rudolf von. A evolução do direito. Salvador: Livraria Progresso. 1953. p. 140.

${ }^{16}$ Ibidem. p. 206.

17 lbidem. p. 91.
} 
grande pensadores HUMBOLDT e STUART MILL fizeram uma ruidosa bancarrota." ${ }^{18}$

A crítica de lhering segue em coerência com o restante de sua teoria. Sua adesão ao utilitarismo foi mitigada pelo pragmatismo; era contra as teorias inspiradas em doutrinas abstratas e desligadas da prática e das necessidades da prática que se insurgia. Estava preocupado com a maneira segundo a qual o Direito se desenvolve na prática, no cotidiano, e para que se manifesta.

Isso se explica. De acordo com LARENZ, o Ihering da "jurisprudência dos interesses" não se interessava tanto pelo conhecimento puro da jurisprudência, como a dogmática, mas sim em encontrar a finalidade do Direito. Isso suscita alguns problemas: onde encontrá-la, e no que pode consistir? Maximização da utilidade? Favorecer a criação de riquezas? Manter a ordem? Sim e não. Quando Ihering fala que toda proposição jurídica deve a sua origem a um fim prático ${ }^{19}$, está dizendo que toda criação jurídica nasceu como proposta de solução de um problema, de promoção de algum interesse, de melhoramento de alguma situação. Que não há criação jurídica que não se deva a alguma percepção de uma situação fática a ser alterada, transformada ou consolidada.

Considerações de natureza puramente utilitarista são uma forma forçada de promoção de uma teleologia do Direito (possivelmente) arbitrária, o que Ihering não propõe. É possível que sejam verdadeiras no plano histórico, em um dado momento, o que Ihering não exclui. Mas, positivamente, e cientificamente, não é o que a sua teoria compreende como sendo a causa do Direito.

\section{DEFINIÇÃO DE DIREITOS}

Ihering critica fortemente a concepção do direito subjetivo como expressão da vontade, geralmente admitidas desde Hegel. A vontade, para Ihering, não era o fundamento do direito, mas apenas a sua força motriz e objeto.

\footnotetext{
18 lbidem. p. 411.

19 lbidem. p. 28.
} 
Para Ihering, dois elementos constituem o princípio do direito subjetivo. Um substancial, que reside no fim prático do direito, produzindo uma utilidade, as vantagens e garantias que este assegura; e outro formal, que se refere a esse fim unicamente como meio, isto é, a proteção do direito, a ação da justiça

Nesse sentido, o direito estaria composto de duas partes: um interesse juridicamente protegido e os meios de defesa para garanti-lo.

Nesse sentido, lhering:

\begin{abstract}
"Cualquiera que sea la diversidad del interés que presenten los diversos derechos, todo derecho establecido es la expresión de un interés reconocido por el legislador que merece y reclama su proteccíon. Los derechos se transforman a medida que cambian los intereses de la vida(...)." ${ }^{20}$
\end{abstract}

Entretanto, é de se notar que, na realidade, a teoria do direito de lhering neste ponto está incompleta. Ocorre que o autor planejava que a sua obra $O$ Fim do Direito consistisse em dois volumes, sendo que no segundo seria tratado o direito não como finalidade, mas seu fim propriamente dito, isto é, a substituição necessária do interesse pela de utilidade, representada pelo conceito de fim prático; este teria sido o fundamento e a razão da criação de todo o Direito.

\title{
5. DIREITO PÚBLICO, DIREITO INTERNACIONAL E DIREITO PRIVADO
}

Acerca do Direito Internacional, Ihering considerava que a coação era condição essencial do direito. Assim, ao firmar-se nessa condição, colocou que ainda que se reconhecesse o Direito Internacional como forma organizada dos deveres do soberano, careceria de meios de realização prática.

Seria, portanto, um Direito aleijado, ao qual não faltaria substância, mas sim o elemento formal de garantia coativa. E, mais ainda, a única forma de superação dessa lacuna, a criação de um tribunal superior internacional com poder coercitivo, resultaria no próprio e lógico desmoronamento do Direito Internacional.

A mesma dificuldade Ihering vê em relação ao Direito Público. O Soberano não pode estar limitado pelas regras que cria, pois aquele a quem

\footnotetext{
${ }^{20}$ IHERING, Rudolf von. La dogmática jurídica. Buenos Aires: Editorial Losada, 1946, p. 183.
} 
cumpre coagir todos os que têm autoridade abaixo de si não pod eter acima de si pessoa que o coaja $^{21}$. O Direito Público seria Direito sem coerção; sua violação importaria em violar Direito vigente, porém sem meios de voltar-se contra o perpetrador.

Nesse sentido:

\begin{abstract}
"Para todos os outros órgãos do poder público, o estado de coação e o direito de coação coincidem. O impulso é-lhes dado do alto, continua em baixo, como um relógio em que as rodas atuam umas sobre as outras. Mas o relógio não pode dar corda em si mesmo, tem de intervir a mão do homem. Essa mão, na constituição monárquica, é o soberano. É ele quem imprime o movimento a todo o mecanismo, é ele no Estado o único que usa da coação sem poder ser também coagido. Por mais que a Constituição Ihe restrinja o poder pela referenda e pela responsabilidade dos ministros, pelo juramento constitucional dos funcionários, etc, por mais esforços que ela faça por cingi-lo à observância das leis, pela garantia moral do julgamento de fidelidade à Constituição, é impossível submetê-lo a uma coação jurídica positiva." ${ }^{22}$
\end{abstract}

\title{
6. O FIM DO DIREITO
}

Primeiramente, é necessário retomar o que Ihering compreende como sendo o fim, ou, no original, o zweck de sua obra. Conforme afirma logo na primeira página:

\begin{abstract}
"A teoria da razão suficiente ensina-nos que nada no universo acontece por si mesmo (causa sui). Todo o acontecimento, isto é, toda a modificação no mundo físico, é a resultando de uma modificação anterior, necessária à sua existência (...) é a lei da causalidade. (...) Esta lei rege também a vontade. (...) Mas com a natureza inanimada essa causa é de essência mecânica. (...) É psicológica quando a vontade intervém: esta procede em vista de um fim, mira a um alvo (Zweck, causa finalis)."
\end{abstract}

Para Ihering, toda vontade humana é um princípio de causalidade para o mundo exterior. Não há volição sem um fim. A satisfação da vontade, nesse sentido, é o fim do querer humano. Dessa forma, um ato sem um fim é algo que Ihering proclama que não pode existir. Por outro lado, o ato em movimento, no mundo exterior, está sujeito às relações de causalidade.

Disso, funda as relações dos homens uns com os outros no autointeresse, isto é, no egoísmo. Se toda vontade humana é um querer dirigido

\footnotetext{
${ }^{21}$ IHERING, Rudolf von. A evolução do direito. Salvador: Livraria Progresso. 1953. p. 273.

22 Ibidem. p. 273.

${ }^{23}$ IHERING, Rudolf von. A evolução do direito. p. 1.
} 
para um fim, cabe a um ente auto-interessado, porém representante do interesse de muitos (ou da maioria, em sentido estrito ou amplo), impor regras e limites que orientarão os atos oriundos da vontade dos particulares. A lei comina penas que dirigem as ações dos particulares, colocando incentivos e desestímulos na balança na qual pesará seus possíveis cursos de ação.

Importante ressaltar que, diferentemente de outros historiadores de sua época, lhering não considerava tal processo como necessariamente inconsciente. Ao contrário, muitas vezes até mesmo sociedades primitivas podem, por manifestação expressa, criar ou modificar uma norma para atingir um fim conhecido e almejado conscientemente.

Assim, o que lhering compreende como sendo o fim do Direito é o cerne do trabalho que desenvolveu sua fase madura. O Estado é considerado a mais elevada expressão da busca por fins organizados - aqueles os quais o indivíduo depende de uma estrutura para alcançar - na sociedade, ficando, inclusive, sob o ponto de vista da organização, até mesmo à frente da lgreja.

O Direito é o instrumento, por excelência, de que se vale o Estado para atingir os fins organizados - os fins daqueles que representa, como pessoa jurídica que é. Todo o Direito, nesse sentido, está calcado no balanceamento dos interesses pessoais dos indivíduos que compõem a sociedade e a mão do Estado, no sentido de garantir que trabalhem para a concreção dos fins organizados da sociedade.

Estes, por sua vez, variam no espaço, no tempo, na história, e de sociedade para sociedade. Mesmo os direitos individuais seriam uma função dos fins organizados: para lhering, nenhum direito individual é sequer compreensível sem o estudo de seu fim social, e só existem porque há um largo domínio da vida social no qual o auto-interesse, operando sozinho, consegue realizar um fim de interesse de todos.

Pode-se dizer, assim, que Ihering, apesar de tudo, resgata o valor do Direito como ciência prática, ainda que por outros meios. Nesse sentido, como coloca:

"No domínio do Direito nada existe senão pelo fim e para o fim; todo o Direito não é mais do que uma criação do fim. (...) Qual é então o fim do Direito? (...) Podemos dizer que o Direito representa a forma da garantia das condições de vida da sociedade, assegurada pelo poder econômico de que o Estado dispõe." 
Assim, pode-se concluir com as seguintes colocações: Ihering foi um gênio que percebeu as insuficiências e os problemas da ciência jurídica de seu tempo, a saber, o formalismo e o antiquarismo excessivos desligados da prática, e tentou corrigi-los utilizando-se também da ciência de seu tempo incluindo-se aí os ensinamentos da dismal science, a economia, e as doutrinas ligadas a ela, a saber, o utilitarismo e o liberalismo econômico, bem como a idéia de homem naturalmente egoísta.

\section{CONSIDERAÇÕES FINAIS}

Nossa conclusão é a de que, enfim, pode-se falar que lhering sofreu influências dos utilitaristas ${ }^{24}$ - corrente filosófica que ganhara força já havia quase um século, e então chegava ao Continente.

No entanto, a extensão dessa influência deve ser ponderada. Ihering, claramente, não era um utilitarista, e tampouco era a "jurisprudência dos interesses" um produto de uma filosofia do Direito de natureza utilitarista. Há semelhanças em algumas premissas, em conclusões e em parte dos métodos, porém as diferenças são preponderantes.

Ihering não reduz o fenômeno jurídico a uma mera equação de utilidades, tanto no que toca a causa final do Direito como a sua causa eficiente. Nem o Direito, como fenômeno histórico, para Ihering, visa a maximização da utilidade, como tampouco é de sua essência buscar tal fim.

A influência que Ihering sofreu dos utilitaristas deve-se mais à época em que viveu e escreveu do que a uma profissão de fé. O século XIX foi a era da objetividade científica e do positivismo, ungidos da filosofia utilitarista ${ }^{25}$. Um pensador do nível de Ihering não poderia jamais simplesmente ignorar - e não ser influenciado de forma alguma - por uma das correntes de pensamento mais influentes do século XIX.

$E$ isso é esperado. Suas obras, pois, vão muito além do Direito puro. Tratam-se de estudos culturais, sociológicos, antropológicos e históricos. A

\footnotetext{
24 "O princípio da utilidade é aquele princípio que aprova ou desaprova todo tipo de ação de acordo com a tendência que pareça ter de aumentar ou diminuir a felicidade das partes cujo interesse está em pauta". BENTHAM, Jeremy. On the principles of morals and legislation, cap 1, par. 2.

${ }^{25}$ V. TAYLOR, Charles. As fontes do self. São Paulo: Loyola, p. 435.
} 
respeito das críticas de Ihering acerca da "jurisprudência dos conceitos" e do "abstratismo" da época, é importante que isso seja lembrado. A fim de realizar uma crítica relevante, não era suficiente questionar a separação entre teoria e prática, mas sim mostrar que a análise puramente teórica pouco ou nada explica, e que a prática existe e se desenvolve independentemente de uma teoria falha ${ }^{26}$. O fim do Direito é a sua serventia prática.

${ }^{26}$ O que explica a sua conhecida posição a favor do ensino e do uso do estudo de casos nas faculdades de Direito. 


\section{BIBLIOGRAFIA}

IHERING, Rudolf von. La dogmática jurídica. Buenos Aires: Editorial Losada, 1946.

IHERING, Rudolf von. O espírito do direito romano. Rio de Janeiro: Alba, 1943.

IHERING, Rudolf von. A evolução do direito. Salvador: Livraria Progresso. 1953.

LARENZ, Karl. Metodologia da ciência do direito. Trad. José Lamego. 3a ed. Lisboa: Calouste Gulbenkian, 1997.

MORRIS, Clarence (org.). The great legal philosophers: selected readings in jurisprudence. Philadelphia: University of Pennsylvania Press, 1997. 